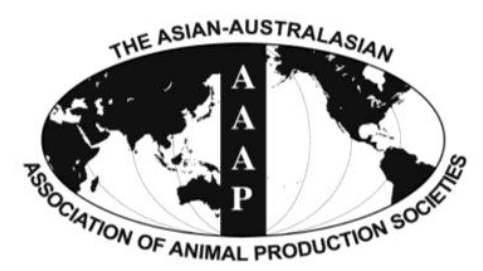

Open Access

Asian Australas. J. Anim. Sci.

Vol. 28, No. 5 : 730-746 May 2015

http://dx.doi.org/10.5713/ajas.14.0593

www.ajas.info

pISSN 1011-2367 elSSN 1976-5517

\title{
Selenium in Pig Nutrition and Reproduction: Boars and Semen Quality - A Review
}

\author{
Peter F. Surai ${ }^{1-4, *}$ and Vladimir I. Fisinin ${ }^{5}$ \\ ${ }^{1}$ Department of Animal Nutrition, Faculty of Agricultural and Environmental Sciences, \\ Szent Istvan University, Gödöllo H-2103, Hungary
}

\begin{abstract}
Selenium plays an important role in boar nutrition via participating in selenoprotein synthesis. It seems likely that selenoproteins are central for antioxidant system regulation in the body. Se-dependent enzyme glutathione peroxidase (GSH-Px) is the most studied selenoprotein in swine production. However, roles of other selenoproteins in boar semen production and maintenance of semen quality also need to be studied. Boar semen is characterised by a high proportion of easily oxidized long chain polyunsaturated fatty acids and requires an effective antioxidant defense. The requirement of swine for selenium varies depending on many environmental and other conditions and, in general, is considered to be 0.15 to $0.30 \mathrm{mg} / \mathrm{kg}$ feed. It seems likely that reproducing sows and boars are especially sensitive to Se deficiency, and meeting their requirements is an important challenge for pig nutritionists. In fact, in many countries there are legal limits as to how much Se may be included into the diet and this restricts flexibility in terms of addressing the Se needs of the developing and reproducing swine. The analysis of data of various boar trials with different Se sources indicates that in some cases when background Se levels were low, there were advantages of Se dietary supplementation. It is necessary to take into account that only an optimal Se status of animals is associated with the best antioxidant protection and could have positive effects on boar semen production and its quality. However, in many cases, background Se levels were not determined and therefore, it is difficult to judge if the basic diets were deficient in Se. It can also be suggested that, because of higher efficacy of assimilation from the diet, and possibilities of building Se reserves in the body, organic selenium in the form of selenomethionine (SeMet) provided by a range of products, including Se-Yeast and SeMet preparations is an important source of Se to better meet the needs of modern pig genotypes in commercial conditions of intensive pig production. (Key Words: Selenium, Boar, Nutrition, Lipids, Antioxidants)
\end{abstract}

\section{INTRODUCTION}

Boar spermatozoa are characterized by high susceptibility to lipid peroxidation (Cerolini et al., 2000).

\footnotetext{
* Corresponding Author: Peter F. Surai. Tel: +44-1292-880-412, Fax: +44-1292-880412, E-mail: psurai@feedfood.co.uk

${ }^{2}$ Department of Microbiology and Biochemistry, Faculty of Veterinary Medicine, Trakia University, Stara Zagora 6000, Bulgaria.

${ }^{3}$ Department of Veterinary Expertise and Microbiology, Faculty of Veterinary Medicine, Sumy National Agrarian University, Sumy, 40021, Ukraine.

${ }^{4}$ Odessa National Academy of Food Technologies, Odessa 65039, Ukraine.

5 All-Russian Institute of Poultry Husbandry, Sergiev Posad, 141311, Russia.

Submitted Aug. 1, 2014; Revised Oct. 14, 2014; Accepted Nov. 23, 2014
}

Indeed, mammalian spermatozoa are unique in structure and chemical composition and contain high proportions of polyunsaturated fatty acids (PUFAs) in the phospholipid fraction of their membranes (Cerolini et al., 2000; Surai, $2002 ; 2006)$. This feature of these highly specialized cells is a reflection of the specific needs of their membranes for high levels of fluidity and flexibility, which are necessary for sperm motility and fusion with the egg. This functional advantage conferred by PUFAs is, however, associated with disadvantages in terms of the susceptibility of sperm to free radical attack and lipid peroxidation.

Therefore, antioxidant protection is a vital element in maintaining sperm membrane integrity, motility and fertilizing ability. It has been suggested (Surai et al., 2001; Surai, 2006) that natural antioxidants (vitamin E, ascorbic acid, and glutathione) together with antioxidant enzymes 
(superoxide dismutase and glutathione peroxidase) build an integrated antioxidant system in mammalian and avian semen capable of protecting it against free radicals and toxic products of their metabolism. The delicate balance between free radical production and antioxidant defense is considered to be an important determinant of boar semen quality and in particular its fertilising ability. In this respect, dietary $\mathrm{Se}$ is an important modulator of semen quality, including the antioxidant systems. The aim of the review is to update existing knowledge related to physiological roles of Se in boar nutrition and reproduction with a special emphasis to antioxidant defences in boar semen.

\section{SELENIUM AND MALE FERTILITY}

The essentiality of selenium for male fertility was shown in the early 1980s. This conclusion was based on the results of a range of different experiments with mammals which can be summarised as follows. In mild deficiency, Se is preferentially retained in rat testes and mammalian semen is considered to contain the highest selenium concentration of all other body tissues. In particular, in human, a significant positive correlation in the selenium concentration was demonstrated between the different reproductive organs with the testis is having the highest concentrations of this element. After ${ }^{75} \mathrm{Se}$ intravenous injection, the highest levels of ${ }^{75} \mathrm{Se}$ were found in the kidney followed by seminal vesicles and testicles. Progressive selenium deficiency was associated with morphological alterations of spermatids and spermatozoa with subsequent complete disappearance of mature germinal cell. Impaired spermatogenesis due to $\mathrm{Se}$ deficiency has been reported in several animal species including pigs (Marin-Guzman et al., 1997; 2000). Specific structural role of phospholipid hydroperoxide glutathione peroxidase (PH-GSH-Px) in spermatozoa was shown (for review and references see Surai, 2006 and Ahsan et al., 2014).

It is generally accepted that Se participates in various physiological functions as an integral part of a range of selenoproteins. The selenoprotein family includes at least 25 eukaryotic proteins. Expression of individual eukaryotic selenoproteins is characterised by high tissue specificity, depends on Se availability, can be regulated by hormones, and if compromised contributes to various pathological conditions (Surai, 2006; Hartfield et al., 2014; Labunskyy et al., 2014; Mangiapane at al., 2014). Protective roles of selenoproteins in pig reproduction is related to necessity for an effective antioxidant defence to prevent negative consequences of over-production of free radicals during semen collection, manipulation (e.g. dilution, storage, etc.) and artificial insemination.

\section{FATTY ACID COMPOSITION OF MAMMALIAN SEMEN}

Lipids are important constituents of the mammalian semen. They serve as structural compounds of the spermatozoa membranes, are precursors of different biologically active compounds (eicosanoids) and can be used for energy production. It is widely accepted that docosahexaenoic fatty acid (DHA) is the most important spermatozoan PUFA in mammals, including man, bull, monkey, ram and boar (Poulos et al., 1973; Cerolini et al., 2000; Surai, 2006). The importance of $C_{22}$ polyunsaturates in relation to male fertility has been shown in humans where the amount of DHA in spermatozoa is positively correlated with sperm motility (Conquer et al., 1999) and with the normal morphology of sperm cells (Lenzi et al., 2000). Therefore, the best morphological pattern corresponded to the highest DHA concentration in the human semen. Similarly, in boar semen DHA and n-3 PUFA

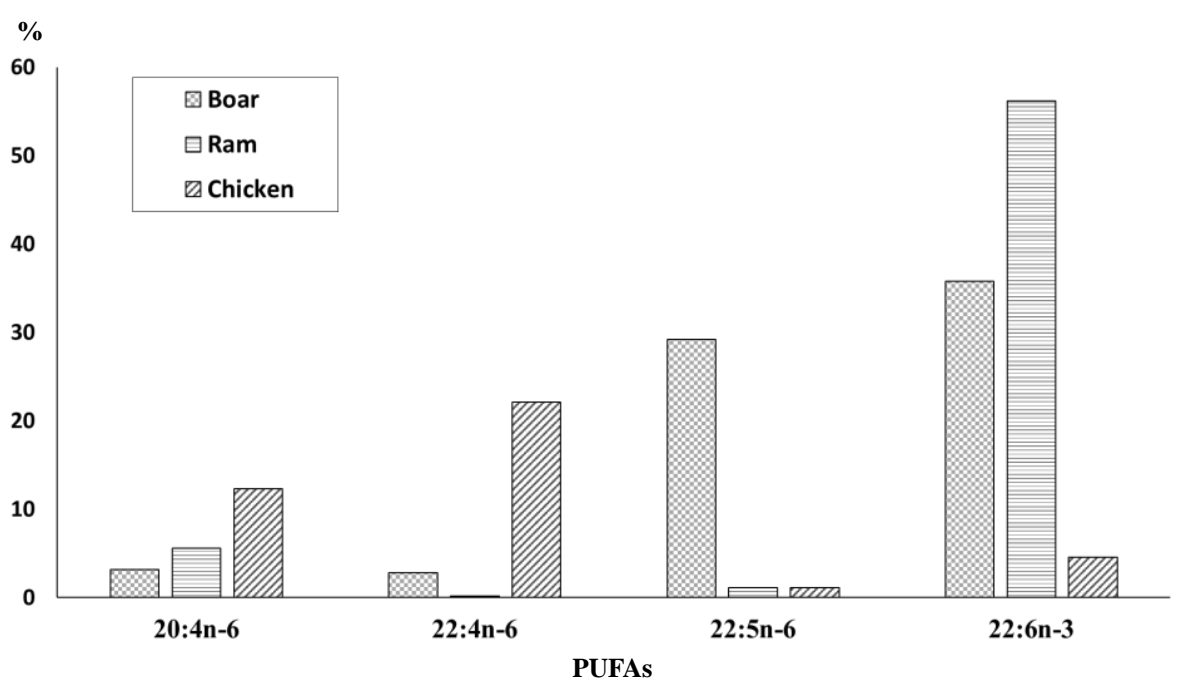

Figure 1. Polyunsaturated fatty acids (percentage of total fatty acids) in spermatozoa phospholipids (Adapted from Surai, 2006). 
were positively correlated with sperm motility, viability, normal morphology and normal plasma membrane (Am-in et al., 2011). In general, in mammalian spermatozoa long chain PUFAs containing 20 to 22 carbon atoms comprise more than $50 \%$ of total fatty acids in the phospholipid fraction (Figure 1).

The biological reason for these species-specific differences in the PUFA profiles of spermatozoa is not clear at present. However, there is a growing body of evidence indicating that the fatty acid composition of sperm membranes, especially levels of PUFA, determines their biophysical characteristics such as fluidity and flexibility as appropriate for their specific functions, including sperm motility and fertilising capacity (Ladha, 1998). For example, increased PUFA concentrations in human spermatozoa were associated with increased sperm membrane fluidity (Comhaire et al., 2000). The very high proportion of long chain PUFA in the mammalian, including boar, spermatozoa predisposes them to lipid peroxidation (Brouwers and Gadella, 2003) and it seems reasonable to suggest that antioxidant protection plays a crucial role in the maintenance of spermatozoan membrane integrity and their fertilising ability (Surai, 2006). Indeed, boar spermatozoa are rich in PUFAs and are vulnerable to lipid peroxidation.

\section{LIPID PEROXIDATION IN SEMEN}

It is somewhat surprising that toxicity of oxygen free radicals to human spermatozoa was reported more than 70 years ago, however, major attention to this subject came in 1970s after publication of several milestone papers by Jones and Mann (for review and references see Surai, 2006). These publications clearly showed that lipid peroxidation:

- Takes place in mammalian spermatozoa

- Caused decline in motility of spermatozoa

- Irreversibly abolished the fructolytic and respiratory activity of spermatozoa

- Increased release of intracellular enzymes from spermatozoa into medium

- Is the major biochemical cause of sperm senescence under storage conditions in vitro

- Caused predominant oxidation of 22:6n-3 and 20:4n-6 fatty acids

Furthermore, those authors also showed that the susceptibility of spermatozoa to peroxidation was increased in cells damaged prior to incubation and that peroxidized PUFAs added to a washed sperm suspension immobilised the spermatozoa rapidly and permanently. Those publications presented results obtained with ram and human semen. However results on lipid peroxidation in other mammalian species have also been published, including boar (Cerolini et al., 2000; Castellano et al., 2010; Satorre et al., 2012). Furthermore, lipid peroxidation in semen has been studied further in detail and several comprehensive reviews have discussed recent findings (Chen et al., 2013; Naher et al., 2013). The conclusion is that lipid peroxidation in mammalian semen is considered to be one of the most important factors causing infertility in man as well as causing decreased sperm quality during the storage of semen from farm animals.

Therefore, the mechanisms by which reactive oxygen species (ROS) disrupt sperm function probably involve the peroxidation of PUFA in the sperm plasma membrane. For example, it has been shown that in human spermatozoa, lipid peroxidation damages the cell plasma membrane, leading to loss of cytoplasmic components and hence to cell death - a process that is considered to play an important role in the pathophysiology of male infertility (Aitken et al., 1993). Similarly, Breininger et al. (2005) showed a negative association between thiobarbituric acid reactive substances (TBARS) and sperm motility of boars $(r=-0.86, p<0.05)$. Furthermore, increased level of malondialdehyde (MDA) in stored boar semen was associated with a rapid loss of motility and membrane integrity (Kumaresan et al., 2009). The reduction in motility might have been due to a ROSinduced lesion in adenosine triphosphate (ATP) utilization or in the contractile apparatus of the flagellum. It was shown that lipid peroxidation and the amount of ROS in the sperm were not related to boar semen freezability (GómezFernández et al., 2013). It is necessary to note that spermatozoa from individual boars can respond in a boardependent manner to different semen-processing techniques, including lipid peroxidation and DNA-fragmentation (Parrilla et al., 2012).

Boar sperm subjected to cooling or freezing undergo many stresses that may damage membrane structure, function and integrity, impairing motility, mitochondrial function, membrane potential and fertility (Radomil et al., 2011). Since boar spermatozoa are rich in PUFAs, they are sensitive to lipid peroxidation. Indeed, adding various antioxidants to the boar semen diluent could have a protective effect during sperm storage and cryopreservation. For example, the freezing extenders with the presence of alginate led to higher superoxide dismutase (SOD) and GSH-Px activities and lower MDA levels, in comparison to the control and improved frozen-thawed boar spermatozoa motility, functional integrity and antioxidative capacity (Hu et al., 2014). These findings are especially important, since prolonged semen storage in liquid nitrogen induced a marked reduction in post-thaw sperm motility, mitochondrial function and plasma membrane integrity in most of the boars (Fraser et al., 2014). In the experiment, post-thaw boar semen exhibited a marked decrease in osmotic resistance of the sperm acrosomal membrane with a significant increase in the sperm cryo-susceptibility to 
induced lipid peroxidation and DNA fragmentation. Antioxidant-prooxidant balance in boar semen is an important regulator of many physiological processes, including sperm attachment to oviductal epithelial cells, capacitation and hyperactivation, binding to the oocyte zona pellucida, acrosome reaction, penetration of the zona, and fusing with and penetrate the oolemma (Bailey et al., 2000). Therefore, impaired sperm membrane function due to lipid and protein oxidation inevitably affects aforementioned processes and decreasing chances of successfully fertilizing an oocyte in vivo.

Therefore, most of the studies on mechanisms and consequences of lipid peroxidation have been associated with human spermatozoa with much less emphasis on boar semen. However, detrimental consequences of lipid peroxidation on boar semen quality are clearly shown. Molecular mechanisms and physiological and pathophysiological consequences of protein oxidation in boar testes and semen await investigations.

\section{ANTIOXIDANT SYSTEMS OF BOAR SEMEN}

During evolution living organisms have developed specific antioxidant protective mechanisms to deal with ROS. Therefore it is only the presence of natural antioxidants in living organisms which enable them to survive in an oxygen-rich environment (Halliwell, 1994). These mechanisms are described by the general term "antioxidant systems". They are diverse and responsible for the protection of cells from the actions of free radicals. These systems include (Surai, 2006):

- natural fat-soluble antioxidants (vitamin E, carotenoids, ubiquinones, etc.);

- water-soluble antioxidants (ascorbic acid, uric acid, taurine, etc.)

- antioxidant enzymes: SOD, GSH-Px and catalase (CAT)

- thiol redox system consisting of the glutathione system (glutathione/glutathione reductase/glutaredoxin/ glutathione peroxidase and a thioredoxin system (thioredoxin/thioredoxin peroxidase/thioredoxin reductase)

The protective antioxidant compounds are located in organelles, subcellular compartments or the extracellular space enabling maximum cellular protection to occur. Thus antioxidant system of the living cell includes three major levels of defence (Surai, 2002; 2006):

The first level of defense is responsible for prevention of free radical formation by removing precursors of free radicals or by inactivating catalysts and consists of three antioxidant enzymes namely SOD, GSH-Px, and CAT plus metal-binding proteins. Since the superoxide radical is the main free radical produced in physiological conditions in the cell (Halliwell, 1994) SOD (EC 1.15.1.1) is considered to be the main element of the first level of antioxidant defense in the cell.

At present, three distinct isoforms of SOD have been identified in mammals, and their genomic structure, cDNA, and proteins have been described (Zelko et al., 2002). It should be mentgioned, that SOD1, or Cu,Zn-SOD, was the first enzyme of this family to be characterised and is a copper and zinc-containing homodimer that is found almost exclusively in intracellular cytoplasmic spaces. It exists as a $32 \mathrm{kDa}$ homodimer and is present in the cytoplasm and nucleus of every cell type examined (Zelko et al., 2002). The second member of the family (SOD2) has manganese (Mn) as a cofactor and therefore called Mn-SOD. It was shown to be a $96 \mathrm{kDa}$ homotetramer and located exclusively in the mitochondrial matrix, a prime site of superoxide radical production (Halliwell and Gutteridge, 1999). Mn-SOD is inducible enzyme and its activity is affected by cytokines and oxidative stress. In 1982, a third SOD isozyme was discovered by Marklund and co-workers and called extracellular superoxide dismutase (EC-SOD), due to its exclusive extracellular location. The EC-SOD is a glycoprotein with a molecular weight of $135,000 \mathrm{kDa}$ with high affinity for heparin. The expression pattern of EC-SOD is highly restricted to the specific cell type and tissues where its activity can exceed that of $\mathrm{Cu}, \mathrm{Zn}-\mathrm{SOD}$ or $\mathrm{Mn}$ SOD.

Superoxide dismutase dismutates the superoxide radical in the following reaction:

$$
2 \mathrm{O}_{2}^{*}+2 \mathrm{H}^{+} \stackrel{\text { SOD }}{\longrightarrow} \mathrm{H}_{2} \mathrm{O}_{2}+\mathrm{O}_{2}
$$

The hydrogen peroxide formed by SOD action can be detoxified by GSH-Px or CAT which reduce it to water as follows:

$$
\begin{aligned}
& \mathrm{H}_{2} \mathrm{O}_{2}+2 \mathrm{GSH} \stackrel{\text { GSH-Px }}{\longrightarrow} \mathrm{GSSG}+2 \mathrm{H}_{2} \mathrm{O} \\
& 2 \mathrm{H}_{2} \mathrm{O}_{2} \stackrel{\text { Catalase }}{\longrightarrow} 2 \mathrm{H}_{2} \mathrm{O}+\mathrm{O}_{2}
\end{aligned}
$$

Transition metal ions also accelerate the decomposition of lipid hydroperoxides into cytotoxic products such as aldehydes, alkoxyl radicals and peroxyl radicals:

$$
\begin{aligned}
& \mathrm{LOOH}+\mathrm{Fe}^{2+} \longrightarrow \mathrm{LO}^{*}+\mathrm{Fe}^{3+}+\mathrm{OH}^{-} \\
& \mathrm{LOOH}+\mathrm{Fe}^{3+} \longrightarrow \mathrm{LOO}^{*}+\mathrm{Fe}^{2+}+\mathrm{H}^{+}
\end{aligned}
$$

Therefore, metal-binding proteins (transferrin, lactoferrin, haptoglobin, hemopexin, metallothionenin, ceruloplasmin, ferritin, albumin, myoglobin, etc.) also belong to the first level of defense. 
Unfortunately, this first level of antioxidant defense in the cell is not sufficient to completely prevent free radical formation and some radicals do escape through the preventive first level of antioxidant safety screen initiating lipid peroxidation and causing damage to DNA and proteins. Therefore, the second level of defense consists of chainbreaking antioxidants - vitamin E, ubiquinol, carotenoids, vitamin A, ascorbic acid, uric acid and some other antioxidants. Glutathione and thioredoxin systems also have a substantial role in the second level of antioxidant defense. Chain-breaking antioxidants inhibit peroxidation by keeping the chain length of the propagation reaction as small as possible. Therefore, they prevent the propagation step of lipid peroxidation by scavenging peroxyl radical intermediates in the chain reaction (Surai, 2002):

$$
\mathrm{LOO}^{*}+\mathrm{Toc} \longrightarrow \mathrm{Toc}^{*}+\mathrm{LOOH}
$$

(LOO* is lipid peroxyl radical; Toc, tocopherol; Toc*, tocopheroxyl radical; $\mathrm{LOOH}$, lipid hydroperoxide). The hydroperoxide formed in aforementioned reaction is detoxified by GSH-Px.

However, even the second level of antioxidant defense in the cell is not able to prevent damaging effects of ROS and reactive nitrogen spacies on lipids, proteins and DNA. In this case, the third level of defense is based on systems that eliminate damaged molecules or repair them. This level of antioxidant defense includes lipolytic (lipases), proteolytic (peptidases or proteases) and other enzymes (DNA repair enzymes, ligases, nucleases, polymerases, proteinases, phospholipases and various transferases).

Indeed, the first level of antioxidant defense of boar semen consists of SOD, CAT, and GSH-Px (Strzezek et al., 1999; Kowalowka et al., 2008; Koziorowska-Gilun et al., 2011). Initially, purification and characterization of SOD from supernatant fractions prepared from cold-shocked boar spermatozoa showed it to be cyanide-sensitive, to have a mol.wt. of 31,000 and to contain $\mathrm{Cu}$ and $\mathrm{Zn}$.

In fact, a secretory extracellular form of SOD (ECSOD) was purified to homogeneity from boar seminal plasma (Kowalowka et al., 2008). The molecular properties and specificity of SOD confirmed that the purified enzyme is an extracellular form of $\mathrm{Cu} / \mathrm{Zn}$-SOD occurring in boar seminal plasma. The antigenic determinants of SOD isolated from boar seminal plasma and spermatozoa were similar to each other (Orzołek et al., 2013). Boar seminal plasma contains also CAT and glutathione (KoziorowskaGilun et al., 2011). However, it appears that boar semen is comparatively low in CAT, particularly when contrasted to CAT concentrations in blood and protective roles of CAT (functioning mainly when $\mathrm{H}_{2} \mathrm{O}_{2}$ concentration is largely above physiological levels) in antioxidant defense of mammalian semen is questionable (Vernet et al., 2004). It should be noted, that peroxisomes that contain CAT are eliminated from germ cells during spermatogenesis (Nenicu et al., 2007). Data concerning antioxidant enzymes in boar semen are variable. For example, SOD activity was measured in boar spermatozoa but GSH-Px activity was not detected (Cerolini et al., 2001). In contrast, both enzymatic activities were measured in seminal plasma. A large variability in SOD activity was found among the spermatozoa of different boars, with activities ranging from 167.7 to 926.6 and from 3.32 to $13.8 \mathrm{IU} / \mathrm{mg}$ protein in spermatozoa and seminal plasma, respectively (Cerolini et al., 2001).

Antioxidants secreted by the reproductive tract protect spermatozoa against the toxic effects of ROS after ejaculation. It was shown that the scavenging potential of the seminal plasma is dependent on the contributions of different antioxidants, originating in various fluids of boar reproductive tract (Koziorowska-Gilun et al., 2011). The authors showed that the cauda epididymidal spermatozoa exhibited high SOD activity and relatively low activity of PH-GSH-Px. The relative amounts of GSH-Px, glutathione reductase, and glutathione-S-transferase activities in the cauda epididymidal spermatozoa were negligible, whereas CAT activity was undetectable. Greater SOD activity was found in the fluids of the cauda epididymis and prostate gland. Furthermore, the prostate gland fluid appeared to be the main source of CAT activity in the seminal plasma, whereas the highest level of GSH-Px activity was derived from the cauda epididymidal fluid (Koziorowska-Gilun et al., 2011).

Since the concentration of CAT in spermatozoa and seminal plasma is low, glutathione and GSH-Px are the main agents that can remove the hydrogen peroxide generated (Surai, 2006). A relatively high GSH level occurs in mouse spermatozoa, while only traces of GSH were found in boar spermatozoa (Luberda, 2005). Furthermore, in boar spermatozoa the activity of GSH-Px and glutathione reductase was also low or undetectable $(\mathrm{Li}, 1975)$. However, GSH is present in boar seminal plasma in a significant amount (Strzezek et al., 1999; Strzezek, 2002).

It was speculated that boar spermatozoa are poorly adapted to counteract the toxic effects of induced ROS (Strzezek et al., 2005) because of comparatively low levels of SOD and the lack of GSH-Px in the seminal plasma. The author suggested that main compounds responsible for antioxidant potential of the seminal plasma are Lglutathione, L-ergothioneine and L-ascorbic acid. However, boar seminal plasma contains only moderate concentration of ascorbic acid (Audet et al., 2004). It is interesting that vitamin $\mathrm{E}$ was not detected in boar seminal plasma (Audet et al., 2004) and its concentration in boar sperm comprised less than $10 \%$ of the plasma vitamin E level (Audet et al., 2009). Nevertheless, the ability to protect sperm against 
oxidative damage is of particular importance in the artificial reproduction industry because of the increased production of ROS by the sperm cell during processing (Bathgate, 2011).

Observations that addition of antioxidants to boar semen improves sperm quality provide indirect evidence for the damaging effects of ROS on sperm function. In our previous study it was shown that boar sperm viability progressively decreased during storage and vitamin $\mathrm{E}$ inclusion into the diluent significantly inhibited this trend (Cerolini et al., 2000). In particular vitamin E inclusion decreased significantly peroxidation (TBARS production of spermatozoa). Spermatozoa stored in the treatment diluent became rapidly enriched in alpha-tocopherol with a concomitant decrease of vitamin E content in the medium. The inclusion of alpha-tocopherol into the diluent was effective in totally preventing the significant decrease of 22:6n3 observed in sperm phospholipid in the control samples during the storage period. Semen cryopreservation is considered to increase the production of ROS leading to damages to sperm membranes (Buhr et al., 1994; Chatterjee et al., 2001). Addition of GSH to the thawing media resulted in a lower number of capacitated viable spermatozoa, a decrease in the number of spermatozoa with changes in the sulfhydryl groups in membrane proteins, a reduction of the ROS generation, a lower chromatin condensation, and a higher penetration ability of oocytes in vitro and a higher proportion of decondensated sperm heads (Gadea et al., 2005). Boar sperm motility, viability and acrosome reaction increased significantly in sodium selenite (SS), selenomethionine (SeMet) and Vit-E (5.5 $\mu \mathrm{g} / \mathrm{L}$ and 1.0 $\mathrm{mM}$, respectively) compared with the control (Tareq et al., 2012). Furthermore, treatment of the sperm with SeMet and SeMet+Vit-E in the presence of $300 \mu \mathrm{M}$ ammonia also resulted in a significant increase of the same semen quality parameters. Clearly, there is a need for further elucidation of the composition and efficacy of antioxidant defense system in boar semen.

Although excessive production of ROS are usually detrimental to spermatozoa, there is a growing body of evidence indicating that low levels of ROS are involved in the physiological control of a range of mammalian sperm functions (Surai, 2006). Therefore, in various attempt to decrease lipid and protein oxidation in boar semen during storage by adding various antioxidants into the medium (diluents) one should be very careful because ROS mediate capacitation of boar spermatozoa by various signaling pathways, such as the extracellular signal-regulated kinase pathway, which phosphorylates different proteins depending on their molecular mass (Awada et al., 2009; Awda and Buhr, 2010). In fact, the authors demonstrated that there was a time-dependent, significant increase in the percentage of acrosome reactions seen in boar sperm exposed to a
ROS-generating system and then incubated in capacitating medium. In general, low concentrations of ROS can induce hyperactivation, capacitation, sperm-oocyte fusion and acrosomal loss and high ROS concentrations inhibit spermoocyte fusion, decrease motility and damage DNA (for review see Surai, 2006).

Enhancement of the antioxidant capacity of semen by nutritional means could present a major opportunity for improving male fertility. The beneficial consequences of effective protection against lipid peroxidation are likely to result from two related mechanisms (Surai, 2006). Firstly, defense against peroxidative damage is essential to prevent any reduction in functionally important C20-22 PUFA levels of spermatozoan phospholipids and to maintain the structural integrity of the spermatozoa. Secondly, minimisation of lipid peroxidation will prevent accumulation of the toxic products of peroxidation. Additional possibilities may also be envisaged for the use of antioxidants in improving the viability of semen during cryopreservation.

Taking into account data showing crucial role of selenoproteins in cellular redox homeostasis and increased selenoprotein expression in response to various stresses (Surai, 2006) it is clear that an importance of semen antioxidant defences and optimal Se nutrition of boars is difficult to overestimate.

\section{GLUTATHIONE PEROXIDASE IN BOAR SEMEN}

Since hydrogen peroxide and lipid peroxides are toxic for the spermatozoa (Walczak-Jedrzejowska et al., 2013; Wright et al., 2014), GSH-Px plays an important role in protecting cell membrane lipid from peroxidation, thus maintaining the integrity of the cell (Flohe and Zimmermann, 1970). In fact, GSH-Px in the sperm is considered to be the main enzyme, which removes peroxides and thereby protects cells against damage caused by free radicals and the products of lipid peroxidation in vivo (Griveau et al., 1995).

In mammals 8 forms of GSH-Px have been characterised and five of those are Se-dependent (for review, see Brigelius-Flohé and Maiorino, 2013), including a classical cytosolic glutathione peroxidase (cGSH-Px or GSH-Px1), gastrointestinal glutathione peroxidase (GIGSH-Px, GSH-Px2), plasma glutathione peroxidase (pGSH-Px, GSH-Px3), phospholipid glutathione peroxidase (GSH-Px4, PH-GSH-Px) and so called GSH-Px6, a close homologue to GPx3, which is a selenoprotein in humans but non-Se-GSH-Px in rodents and other species (for review see Surai, 2006). Other non-Se-GSH-Px includes GSH-Px-5, an epididymis-specific Cys-GSH-Px in mice, rats, pigs, monkey and humans showing a homology to GSH-Px3; GSH-Px7, a non-Se homolog to GSH-Px4 and 
GSH-Px8, a recently described membrane protein of the endoplasmic reticulum (Brigelius-Flohé and Maiorino, 2013). It should be mentioned that both Se-dependent and Se-independent GSH-Px are working in concert providing antioxidant protection in various tissues. In particular, it has been suggested that the Se-independent GSH-Px5 could function as a back-up system for Se-dependent GSH-Px (Vernet et al., 1999). For example, following dietary Se deprivation it was shown that the epididymis is still efficiently protected against increasing peroxidative conditions. In fact, the caput epididymis of seleniumdeficient animals showed a limited production of lipid peroxides, a total GSH-Px activity which was not dramatically affected by the shortage in selenium availability and an increase in GSH-Px 5 mRNA and protein levels was observed (Vernet et al., 1999).

Ursini et al. (1985) reported that a specific form of GSH-Px, which used a phosphatidyl choline hydroperoxide as a substrate (PH-GSH-Px), was Se-dependent. They showed that the enzyme was a monomer of $23 \mathrm{kDa}$. It contained one g-atom Se/22 $000 \mathrm{~g}$ protein. Se was found there in the selenol form. The kinetic data were compatible with 'classical' glutathione peroxidase. The second-order rate constants $\left(\mathrm{K}_{1}\right)$ for the reaction of the enzyme with the hydroperoxide substrates indicated that, while $\mathrm{H}_{2} \mathrm{O}_{2}$ is reduced faster by the $\mathrm{cGSH}-\mathrm{Px}$, linoleic acid hydroperoxide is reduced faster by PH-GSH-Px. The authors suggested that PH-GSH-Px was active at the interface of the membrane and the aqueous phase of the cell. Indeed, $\mathrm{PH}-$ GSH-Px is distinguished from classical GSH-Px as it is active in monomeric form and has a different amino acid composition (Sunde, 1994).

In fact, there are three isoforms of GSH-Px4, namely, a cytosolic (cGSH-Px4), a mitochondrial (mGSH-Px4) and sperm nuclear GSH-Px4 (snGSH-Px4). It has been proven that cGSH-Px4 is ubiquitously distributed in cells, while mGSH-Px4 and snGSH-Px4 are mainly expressed in testis with only marginal amounts in other tissues (BrigeliusFlohé and Maiorino, 2013). It is synthesized as a long form (L-form; $23 \mathrm{kDa}$ ) and a short form (S-form, $20 \mathrm{kDa}$ ) from mRNA that is transcribed from two initiation sites in exon Ia of PH-GSH-Px genomic DNA (Imai and Nakagawa, 2003). S-form PH-GSH-Px is the non-mitochondrial PHGSH-Px and L-form PH-GSH-Px is the mitochondrial PHGSH-Px. The third form of PH-GSH-Px, a $34 \mathrm{kDa}$ selenoprotein, was detected in rat sperm nuclei and called sperm nuclei GSH-Px (snGSH-Px), which acts as a protamine thiol peroxidase and form disulfide cross-links among these proteins, thus stabilizing and protecting DNA (Schneider et al., 2009). The PH-GSH-Px is unique in its capability of reducing ester lipid hydroperoxides even if they are incorporated in biomembranes or lipoproteins. For other members of GSH-Px family, preliminary release of peroxides from the membrane by such enzymes as phospholipase $\mathrm{C}$ is an essential part of detoxification.

It is well known that PH-GSH-Px is widely expressed in normal tissue, and especially high in testis (Guerriero et al., 2014), where it has an important role in spermatogenesis and sperm function and is under gonadotropin control. In this organ a relevant PH-GSH-Px activity is strongly linked to mitochondria of cells undergoing differentiation to spermatozoa.

The most extraordinary discovery about PH-GSH-Px is related to its polymerisation and conversion from active enzyme to the structural protein. In fact, PH-GSH-Px protein was identified as the major constituent of the keratin-like material that embeds the helix of mitochondria in midpiece of spermatozoa (Ursini et al., 1999; Foresta et al., 2002). Indeed failure of the expression of mitochondrial PH-GSH-Px in spermatozoa is considered to be one of the causes of oligoasthenospermia in infertile men (Imai et al., 2001). PH-GSH-Px has the strong binding capacity to the sperm cell tails and to the sperm heads. The PH-GSH-Px activities in tissues of rats fed the Se-deficient basal amino acid diet were $41 \%, 50 \%, 26 \%$, and $25 \%$ of the Se-adequate PH-GSH-Px activities in liver, heart, kidney, and lung respectively (Lei et al., 1995). The authors showed that testis had a 15-fold higher PH-GSH-Px activity than liver and kidney, and a 25-fold higher PH-GSH-Px activity than heart and lung. Furthermore, it was shown that PH-GSH-Px mRNA levels were not affected by Se deficiency. Therefore, the pivotal link between Se, sperm quality and male fertility is PH-GSH-PX, the enzyme responsible for the production of the correct architecture of the midpiece of spermatozoa.

Initially, it was shown that GSH-Px activity in boar seminal plasma was very low (Saaranen et al., 1989). However, in later publications GSH-Px activity was successfully determined in boar seminal plasma (Kolodziej and Jacyno, 2005; Marin-Guzman et al., 1997; Koziorowska-Gilun et al., 2011). It was shown that in boar seminal plasma Se-dependent form of GSH-Px comprised from $80.7 \%$ up to $90.8 \%$ total enzymatic activity (Cerolini et al., 2001). It seems likely that relationship between GSHPx activity and boar semen quality depends on many factors and is not always straightforward. The levels of GSH-Px activity detected in boar seminal plasma from normal ejaculates were nearly three times as high as GSH-Px activity levels in spermatozoa (Jelezarsky et al., 2008). In fact, the authors confirmed the presence of GSH-Px with molecular weight $20 \mathrm{kDa}$ in boar seminal vesicles, prostate, bulbourethral glands, and spermatozoa, but not in seminal plasma. Furthermore, no immune reaction against GSH-Px was present in boar accessory sex gland secretions and seminal plasma. The PH-GSH-Px in boar semen was shown to be affected by Se status (Martins et al., 2014) and organic $\mathrm{Se}$ in the boar diet positively affected PH-GSH-Px gene 
expression in boar testis (Speight et al., 2012). Aforementioned data clearly indicate that forms and protective functions of GSH-Px in boar semen need further investigation. It is important to mention that only optimal Se status provides an effective antioxidant protections, since activities of antioxidant enzymes (GSH-Px and CAT) decreased in livers of animals (mice) fed the marginal or excess dose of $\mathrm{Se}$ as compared to those in the Se-adequate group (Zhang et al., 2013).

Aforementioned data indicate that main attention has been paid to GSH-Px as an important element indicating Se status and potentially antioxidant defenses. However, current evidence suggests that other Se-proteins could be even more important than GSH-Px for Se action and that optimal levels may depend upon the form of Se being ingested (Ferguson et al., 2012).

\section{PRACTICAL ASPECTS OF BOAR SELENIUM NUTRITION}

An extensive work on effects of selenium on boar semen quality has been conducted at the Columbus State University. For example, Marin-Guzman et al. (2000) showed that $\mathrm{Se}$ is involved in a regulation of spermatozoa maturation in the epididymis. They used 10 mature boars ( $\mathrm{n}$ $=[2$ to 3$] /$ treatment group) which were fed from weaning to 18 months of age diets fortified with two levels of supplemental Se (0 or $0.5 \mathrm{ppm})$ or vitamin E (0 or 220 IU/kg diet). The low-Se diet caused changes in spermatozoa: the mitochondria in the tail midpiece were more oval with wider gaps between organelles and the plasma membrane connection to the tail midpiece was not tightly bound as when boars were fed Se. Furthermore, sperm ATP concentration was decreased and percentage of immature spermatozoa with cytoplasmic droplets increased when boars were fed the low-Se diet (Marin-Guzman et al., 2000). It seems likely that, Se has a role in establishing the number of boar spermatozoal reserves and Sertoli cells. For example, when boar's diet was supplemented with Se 0 or $0.5 \mathrm{ppm}$ for 18 months, testicular sperm reserves were higher in boars fed on the high Se diet Marin-Guzman et al. (2000a). In addition, the boars fed dietary Se had also a greater number of Sertoli cells and round spermatids at 6.2 month of age and by 18 month of age they also had more secondary spermatocytes. It is well known that both Se and vitamin $\mathrm{E}$ are involved in a regulation of animal reproduction. Furthermore, low Se in the diet had a greater detrimental effect on semen quality than diets inadequate in vitamin E. In particular, boars fed the nonfortified Se diets had sperm with lower motility and a higher percentage of sperm cells with bent and shoehook tails (Marin-Guzman et al., 1997). Therefore, Se-supplementation improved sperm motility and prevented its decline over the 16-week
Table 1. Effect of Se on boar*

\begin{tabular}{|c|c|c|}
\hline \multirow[t]{2}{*}{ Item } & \multicolumn{2}{|c|}{$\begin{array}{l}\text { Dietary selenium } \\
\text { supplementation }\end{array}$} \\
\hline & 0.0 & 0.5 \\
\hline Liver Se (mg/kg) & 0.54 & 1.15 \\
\hline Liver GSH-Px (U/g) & 2.30 & 13.9 \\
\hline Testis Se (mg/kg) & 0.30 & 0.80 \\
\hline Testis GSH-Px (U/g) & 1.19 & 1.24 \\
\hline \multicolumn{3}{|l|}{ Semen } \\
\hline Volume (mL) & 160 & 163 \\
\hline Sperm concentration $\left(\right.$ no. $\left.\times 10^{9}\right)$ & 290 & 253 \\
\hline Total sperm $\left(\right.$ no. $\left.\times 10^{9}\right)$ & 43.5 & 43.5 \\
\hline GSH-Px (U/mL) & 33.0 & 71.0 \\
\hline $\mathrm{Se}(\mathrm{mg} / \mathrm{kg})$ & 0.03 & 0.13 \\
\hline \multicolumn{3}{|l|}{ Seminal plasma } \\
\hline $\mathrm{Se}(\mathrm{mg} / \mathrm{kg})$ & 0.02 & 0.06 \\
\hline GSH-Px (U/mL) & 12.3 & 37.7 \\
\hline \multicolumn{3}{|l|}{ Sperm } \\
\hline $\mathrm{Se}(\mathrm{mg} / \mathrm{kg})$ & 0.42 & 0.94 \\
\hline GSH-Px (U/g) & 579 & 977 \\
\hline \multicolumn{3}{|l|}{ Sperm production/g testis $\left(\right.$ no $\left.\times 10^{6}\right)$} \\
\hline $5.4 \mathrm{mo}$ & 39.4 & 50.7 \\
\hline $6.2 \mathrm{mo}$ & 65.9 & 73.0 \\
\hline $9 \mathrm{mo}$ & 64.0 & 89.8 \\
\hline $18 \mathrm{mo}$ & 92.4 & 163.8 \\
\hline \multicolumn{3}{|l|}{ Semen quality } \\
\hline $\begin{array}{l}\text { ATP concentration } \\
\text { (nmoles ATP } / 10^{6} \text { spermatozoa) }\end{array}$ & 1.15 & 1.55 \\
\hline Sperm motility (\%) & 60.4 & 87.9 \\
\hline Normal sperm (\%) & 24.2 & 61.9 \\
\hline Fertilization rate ( $\%$ of eggs) & 73.0 & 99.0 \\
\hline Accessory sperm (no./oocyte) & 14.0 & 60.0 \\
\hline
\end{tabular}

GSH-Px, glutathione peroxidase; ATP, adenosine triphosphate.

* Adapted from Mahan et al. (2002).

collection period and the percentage of normal sperm was approximately 3-fold higher when the Se-fortified diet was fed to boars (Mahan et al., 2002; Table 1). At the same time, the semen from boars fed the nonfortified Se diet had a lower fertilisation rate of oocytes with fewer accessory sperm penetrating the zona pellucida. Selenium supplementation has been shown to increase boar sperm GSH-Px activity (Marin-Guzman et al., 1997). Indeed, Se has been found in high concentrations in testes and epididymis of boars, suggesting that it is likely to play an important role for the production and maturation of sperm (Marin-Guzman et al., 1997; 2000). From the results presented above, it is obvious that Se may have several functional roles in the testes development and sperm function, including a structural role in the development of the spermatozoal midpiece and the Sertoli cells as well as being a component of GSH-Px in the sperm. In the case of Se deficiency, a reduction in the percentage of normal 
spermatozoa is observed accompanied by a reduction in sperm motility. In particular, Se supplementation of the male diet is needed to maintain sperm membrane integrity during in vitro sperm manipulation including artificial insemination (Surai, 2006). Similar, in an earlier work it was shown that diets supplemented with Se from sodium selenite increased the number of spermatozoa ejaculated (Segerson et al., 1981).

In this respect, a choice of Se sources in the male diet is of great importance. Recently it has been shown that $\mathrm{Se}$ is assimilated from organic sources much more efficiently compared to commonly used selenite (Mahan et al., 1999). This can be translated into higher Se accumulation in the animal tissues and building a selenium reserve, which can be effectively used in stress conditions. Data on the effect of different forms of Se on boar reproduction are summarised in Table 2.

When a total of 10 boars were divided into 2 groups and fed a diet supplemented with $0.45 \mathrm{mg} / \mathrm{kg}$ Se in the form SS or the same amount Se as a mixture of $0.15 \mathrm{mg} / \mathrm{kg}$ as SS plus $0.3 \mathrm{mg} / \mathrm{kg} \mathrm{Se}$ as Se-Yeast for 84 days there was no effect of additional organic Se on boar semen quality (Thongchalam et al., 2012). Dietary supplements with 0.6 $\mathrm{mg}$ organic $\mathrm{Se} / \mathrm{kg}$ of feed mixture improved antioxidant potential of breeding boars ejaculate: increased Se level, GSH-Px activity, GSH/(oxidized glutathione [GSSH]) ratio and total antioxidant activity (Horky et al., 2012). In an experimental setup a total of 60 boars were randomly allocated at Day 0 into 2 groups. Group A received the ration supplemented with selenium as $\mathrm{SS}(0.4 \mathrm{mg} / \mathrm{kg})$ whereas Group B fed the same diet supplemented with selenium as Se-Yeast $(0.4 \mathrm{mg} / \mathrm{kg})$ and semen quality was assessed during 4 months (Lopez et al., 2010). It was shown that changing from inorganic Se to organic Se in the diet of boars increased sperm concentration but reduced some motility parameters (e.g. straightforward movement) and resistance to oxidative stress. In another experiment crossbred boars were weaned at $28 \mathrm{~d}$ of age and randomly assigned to 1 of 3 dietary treatments: i) basal diets (BD) containing $0.034 \mathrm{mg} / \mathrm{kg} \mathrm{Se}, \mathrm{BD}+0.3 \mathrm{ppm} \mathrm{Se}$ as $\mathrm{SS}$ or $\mathrm{BD}+0.3 \mathrm{ppm}$ Se as Se-Yeast and used in 3 experiments $(\mathrm{n}=$ 10 boars/dietary treatment) (Speight et al., 2012a). It was shown that Se-Yeast and SS did not affect semen quality (fresh or extended) and its fertilizing ability, while SS decreased percentage of sperm with abnormal head in comparison to BD. Furthermore, there was a trend $(\mathrm{p}=$ 0.11 ) for Se-Yeast to improve fertility. The negative effects of intensive semen collection on semen quality were least pronounced in boars fed diets supplemented with Se-Yeast. Furthermore, Se-Yeast was more effective than SS in Se accumulation in tissues and positively affected PH-GSH-Px gene expression in boar testis (Speight et al., 2012).

In a recent study a total of 18 boars were divided into 3 groups, including a control group fed a non-supplemented basal diet and two experimental groups fed the basal diet supplemented with $0.3 \mathrm{ppm}$ selenium in either an organic (Se-Yeast) or inorganic form (selenite, Lovercamp et al., 2013). Boars were fed dietary treatments from weaning at $21 \mathrm{~d}$ of age until the study was terminated when they were $383 \mathrm{~d}$ of age. It was demonstrated that boars fed the Sesupplemented diet had increased plasma levels of selenium independently on the Se form used. Furthermore, dietary treatment did not affect semen quality including volume, concentration, total sperm in the ejaculate, sperm motility, progressive motility, morphology, lipid peroxidation. It is also interesting to note that Se supplementation was not effective in improvement of quality of extended semen stored post collection. Selenium levels in the semen and GSH-Px activity were not affected by dietary treatments. Unfortunately, the authors did not show the background level of Se in the diet and it is impossible to determine if the basic diet was adequate in selenium. Similar results were obtained when a total of 12 boars were divided into 3 groups: CON (Control), fed on the diet supplemented with $\mathrm{Se}$ at $0.3 \mathrm{ppm}$ as SS; INO (Inorganic), supplemented with Se at $0.5 \mathrm{ppm}$ as SS and ORG (Organic), supplemented with Se at $0.5 \mathrm{ppm}$ as Se-Yeast, for 10 weeks (Martins et al., 2014). Replacing sodium selenite with Se-Yeast at 0.5 $\mathrm{mg} / \mathrm{kg}$ dietary supplementation was associated with a significant increase in PH-GSH-Px activity, but did not improve chilled semen viability in $72 \mathrm{~h}$. In fact, abnormal spermatozoa head percentage and proximal droplet percentage significantly decreased, but abnormal tail percentage significantly increased due to Se-Yeast dietary supplementation.

Aforementioned results indicate that effects of dietary Se on boar reproduction depend on the basic level of Se in the diet. In the case when Se level in the diet is comparatively low (0.06 to $0.07 \mathrm{mg} / \mathrm{kg}$, Marin-Guzman et al., 1997; 2000), there were characteristic detrimental changes in testes structure. In another study, having even lower background Se level $(0.034 \mathrm{mg} / \mathrm{kg}$, Speight et al., 2012a), an additional Se supplementation did not affect boar semen quality. Unfortunately, in recent studies (Horky et al., 2012; Thongchalam et al., 2012; Lovercamp et al., 2013; Martins et al., 2014) information about background Se levels in the basic diets is not available. However, based on the results presented one could suggest that the background dietary Se level was adequate to maintain boar reproduction and as a result an additional Se supplementation did not change reproductive performance and semen quality. It should be also mentioned that aforementioned trials done with boars were performed on very low number of animals (the maximum number is 10 boars per of replicate). Clearly, taking into account the large variability in reproductive paframeres between individual 
Table 2. Results of recent trials on effects of Se on boar reproduction

\begin{tabular}{l}
\hline Experimental design \\
\hline A total of 12 boars were divided into 3 groups: \\
0.3 ppm selenite (SS); 0.5 ppm selenite and 0.5 \\
ppm Se-Yeast (SY) for 10 weeks, semen storage - \\
$72 \mathrm{~h}$; No data on Se in a basal diet \\
A total of 18 boars were divided into 3 groups: \\
basal diet (BD), no Se suppl., BD+0.3 ppm SS \\
and BD+0.3 ppm SY from day 21 up to day 383 ; \\
No data on Se in basal diet \\
Crossbred boars were weaned at 28 d of age and \\
randomly assigned to 1 of 3 dietary treatments: I) \\
BD containing $0.034 \mathrm{mg} / \mathrm{kg}$ Se, BD+0.3 ppm SS \\
or BD+0.3 SY and used in 3 experiments (n $=10$ \\
boars/dietary treatment).
\end{tabular}

The same treatment design as Speight et al., 2012; Boars were grown until body weight 137 $\mathrm{kg}$.

A total of 60 boars were randomly allocated at Day 0 into 2 groups. Group A received the ration supplemented with SS $(0.4 \mathrm{mg} / \mathrm{kg})$ whereas Group B was supplemented with SY $(0.4 \mathrm{mg} / \mathrm{kg})$. The sperm quality was investigated during 4 months. No data on Se in a basal diet

A total of 28 boars were divided to 4 experimental groups. Each group was supplemented with SY or SS $(0.3$ and $0.6 \mathrm{mg}$ $\mathrm{Se} / \mathrm{kg}$ ). The duration of the experiment was 18 weeks. No data on Se in a basal diet

A total of 10 boars divided into 2 groups fed a diet supplemented with $0.45 \mathrm{mg} / \mathrm{kg} \mathrm{Se}$ in the form SS or SY $(0.15 \mathrm{SS}+0.3 \mathrm{SY})$ for 84 days

A total of 25 boars were fed diets without Se supplementation (12) or supplemented with 0.5 $\mathrm{mg} / \mathrm{kg}$ Se (13) as SS from 5.4 to 18 mo of age; Basal Se level $0.06 \mathrm{mg} / \mathrm{kg}$

A total of 192 boars were used for 3 experiments and fed BD containing $0.063 \mathrm{mg} / \mathrm{kg}$ Se without Se supplementation or supplemented with 0.5 $\mathrm{mg} / \mathrm{kg}$ in the form of SS from weaning. In the experiment 2, 3 boars from each group were used for semen quality assessment from 9 mo of age for 16 weeks; Se in BD, $0.067 \mathrm{mg} / \mathrm{kg}$

The experimental design is the same as in Martin-Guzman, 2000

\section{Effects}

No effects on semen quality, SY increased PH-GSH-Px

activity, but did not improve chilled semen viability

References

Martins et al.,

2014

No effects on semen quality, Se increased in plasma independently of Se form; Se level and GSH-Px activity in semen were not affected

SY and SS did not affect semen quality (fresh or extended) and its fertilizing ability, while SS decreased percentage of sperm with abnormal head in comparison to BD; numerically (but not significantly, $\mathrm{p}=0.11$ ) SY tended to improve fertility. The negative effects of day of semen collection on semen quality were least pronounced in boars fed diets supplemented with SY

No effect of $\mathrm{Se}$ on reproduction organs; SY was more effective in Se accumulation in tissues; SY possitively affected PH-GSH-Px gene expression in testis

Changing from inorganic Se to organic Se in the diet of boars increased sperm concentration but reduced some motility parameters and resistance to oxidative stress.

Lovercamp et al., 2013

Speight et al., 2012a

Dietary supplements with $0.6 \mathrm{mg}$ organic $\mathrm{Se} / \mathrm{kg}$ of feed mixture improve antioxidant potential of breeding boars ejaculate: increased Se level and GSH-Px activity, GSH/GSSH ratio and total AO activity

No effect of SY on semen quality

By 18 mo of age the Se-fed boars had higher numbers of sperm reserves, had more Sertoli cells, more secondary spermatocytes and more round spermatids.

Boars fed the nonfortified Se diet had sperm with lower motilities and a higher percentage of sperm cells with bent and shoehook tails and characterised by a lower fertilization rate of oocytes with fewer accessory sperm penetrating the zona pellucida.

When the low-Se diet was fed the mitochondria in the tail midpiece were more oval with wider gaps between organelles and decreased level of ATP was observed as well as increased number of immature spermatozoa with cytoplasmic droplets. The plasma membrane connection to the tail midpiece was not tightly bound as when boars were fed Se.
Tongchalam et al., 2012

Horky et al., 2012

Marin-Guzman et al., 2000

Marin-Guzman et al., 1997

Marin-Guzman et al., 2000a

PH-GSH-Px, phospholipid hydroperoxide glutathione peroxidase; GSH-Px, glutathione peroxidase; GSSH, oxidized glutathione; AO, antioxidant; ATP, adenosine triphosphate.

males, there is a need to perform trials using a large number of boars to be sure of the conclusions.

The general relationship between selenium and male fertility is shown in Figure 2. Recent data indicate that the antioxidant/prooxidant balance in semen is an important element in maintaining membrane integrity and function including sperm viability and fertilising capacity (Surai, 2006). Therefore, the antioxidant system is a crucial element in male reproduction and dietary selenium has a unique role via antioxidant mechanisms. Since Se levels in 

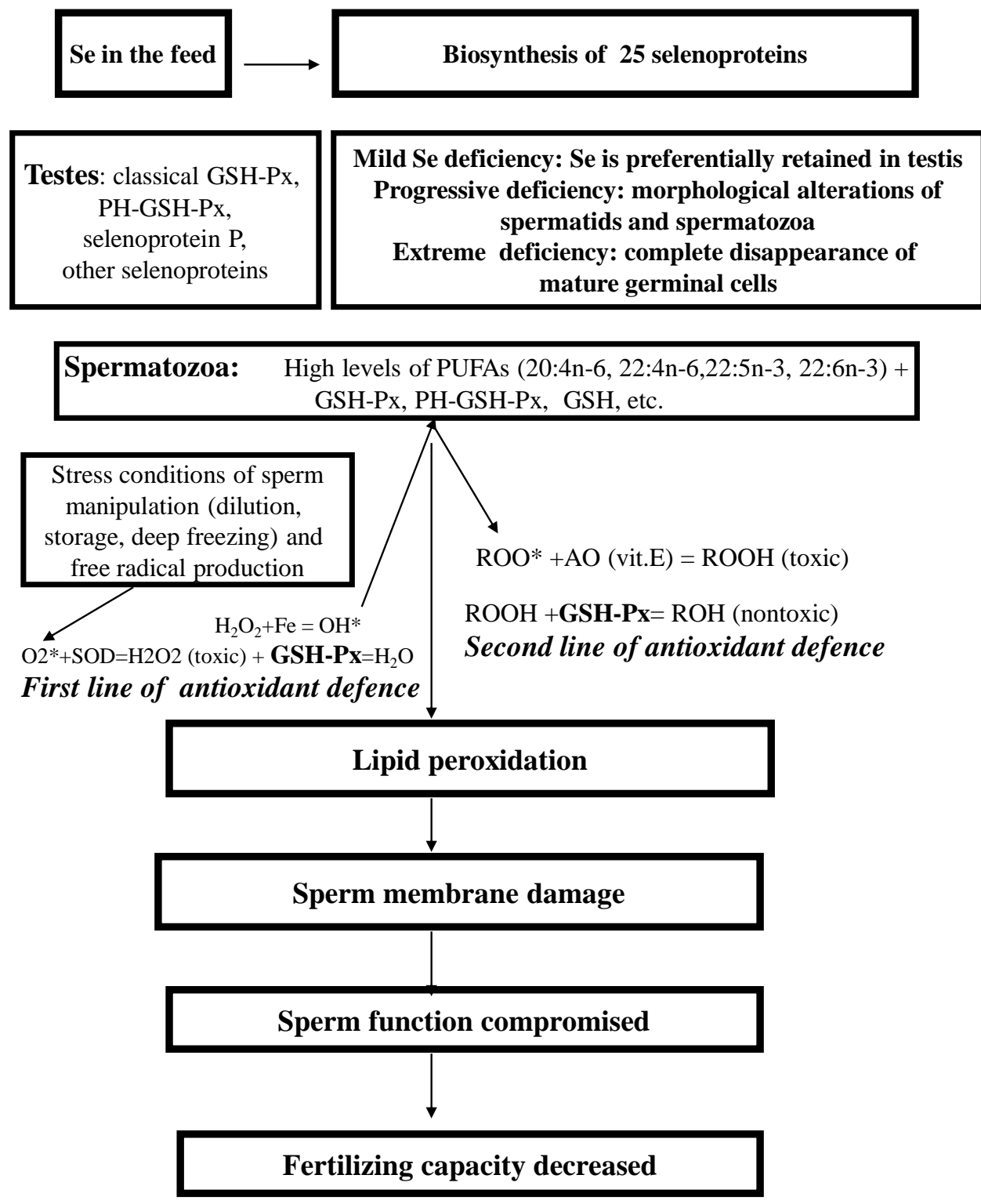

Figure 2. Selenium and male fertility (Adapted from Surai, 2006).

European feedstuffs is substantially lower than in the USA (Surai, 2006) one could expect better response to dietary Se supplementation than can be seen in the USA. The current recommendations on the Se requirements of swine are 0.15 to $0.30 \mathrm{ppm}$ (NRC, 1998), but in commercial conditions this should be increased depending on the level of stress. Indeed, the Se requirements of boars depends on many factors, including season, housing and management conditions, health status, body weight phases and breeds. In fact, genotypes with a higher potential for lean tissue growth sometimes are characterised by lower feed intake, and therefore need more nutritional attention than other genotypes (Surai, 2006). Furthermore, levels of other antioxidants (vitamin E, carotenoids, flavonoids, etc.) and pro-oxidants (unsaturated fat, copper, iron, etc.) in the diet would also affect boar Se requirement. Under experimental laboratory conditions, stressors are generally lower than in commercial pig producing systems and low Se doses could be adequate to maintain optimal GSH-Px activity (Mahan et al., 1999). It could be suggested that boars at big scale commercial farms located in Europe and other areas with low Se dietary background level and having high challenges would needed increased antioxidant defenses and most likely would benefit from additional dietary Se supplementation in the organic form. Indeed, as it is mentioned above, building Se reserves in the body which can be used in stress conditions for additional synthesis of various selenoproteins is the main advantage of organic Se in boar nutrition (Surai, 2006). It should be also mentioned that in the last decade, there has been significant progress in characterizing selenoproteins and understanding their physiological functions (Labunskyy et al., 2014). Indeed, 
there are at least 24 selenoproteins in animal body and Se is involved in regulation of cell growth, apoptosis and modifying the action of cell signalling systems and transcription factors and therefore its adequate dietary supply is a crucial factor for many physiological processes in male body. Furthermore all the antioxidants in the body working cooperatively building an integrated antioxidant system which is regulated at the vita-gene level (Surai, 2006; Calabrese et al., 2012) and thus, it is extremely challenging to measure the effect on semen quality of any single antioxidant alone.

\section{ORGANIC SELENIUM CONCEPT FOR BOAR NUTRITION: A RE-EVALUATION}

In nature, Se exists in two chemical forms, organic and inorganic. Inorganic Se can be found in different minerals in the form of selenite, selenate and selenide as well as in the metallic form. In contrast, in forages, grains and oilseed meals Se is found in organic form, mainly as Se-Met. Therefore, in nature animals receive Se mainly in the form of SeMet (Surai, 2006). Plants absorb Se from the soil in the form of selenite or selenate and synthesise selenoaminoacids, including SeMet, representing about $50 \%$ of the Se in cereal grains and the Se concentration in soil varies significantly (Surai, 2006); and its availability to plants depends on many factors. In the case of acidic soil $\mathrm{pH}$ or low soil aeration, Se can form insoluble complexes with iron hydroxide and become poorly available. Consequently, the Se content of animal feed ingredients also varies. As a result, dietary Se supplementation is an effective means to overcome Se deficiency and to maintain high productive and reproductive performance. The major Se supplements in use for the last 30 years are selenite and selenate-both inorganic forms of Se. The limitations of using inorganic Se are well known: toxicity, interactions with other minerals, low efficiency of transfer to milk, meat and eggs and inability to build and maintain Se reserves in the body (Surai, 2006). Furthermore, a prooxidant effect of the selenite ion is a great disadvantage. Thus, the use of sodium selenite in animal diets has been questioned (Surai, 2006; Fortier et al., 2012). In contrast, SeMet itself is considered to possess antioxidant properties (Schrauzer, 2000). The development and commercialisation of various form of organic Se, containing SeMet as an active form of $\mathrm{Se}$, provides a means of supplying animals with the same form as they could obtain from Se-adequate feed ingredients. This opens a new era in animal nutrition providing opportunities not only for improvement of animal health and productivity but also for production of $\mathrm{Se}$ enriched meat, milk, eggs and other foods considered to be important steps in the improvement of human diets.
Generally speaking, the main advantage of organic Se in boar nutrition, similar to other animal species, including poultry, is coming from Se reserves accumulated in tissues, mainly in muscles, in the form of SeMet (Surai, 2006; Surai and Fisinin, 2014). There are several lines of evidence confirming the idea that $\mathrm{Se}$ accumulated in tissues in the form of SeMet can be available for selenoprotein synthesis (for review see Surai, 2006). In particular, a study with broiler chickens fed organic or mineral Se demonstrated that endogenous Se could be released from tissues, and, thus, that organic Se sources were more efficient in maintaining the GSH-Px level (Payne and Southern, 2005). Aforementioned data indicate that protective effect of organic selenium is more pronounced under stressful conditions (Speight et al., 2012a). Therefore, Se reserves in the body (mainly in the muscles) built in the form of SeMet non-specifically incorporated into the proteins in place of Met could be considered as an important element in increasing adaptive ability of animals (boars) to various stresses. This could increase their reproductive performance in stressful commercial conditions. The benefit of organic selenium in boar diets lies in its efficient absorption, transport and accumulation of body reserves. This results in improved antioxidant status of the testes and semen. As the levels of major natural antioxidants (vitamin E, ascorbic acid and carotenoids) in boar semen are comparatively low (Audet et al., 2004; 2009,2009a), the antioxidant enzymes become a critical arm of antioxidant defense. Therefore, enhanced GSH-Px activity in tissues and semen as a result of organic selenium supplementation of the boar diet may have a positive impact on semen quality in stressful commercial conditions of pig production.

For the last few decades the commercial technology of organic Se production from yeast has been developed (Surai, 2006). Indeed, various commercial forms of Se-Yeast found their way to the market place and shown to be effective sources of Se for poultry and animal production (for review see Surai, 2006; Fisinin et al., 2008; Surai et al., 2010). In addition, advantages and disadvantages of Se-Yeast usage in poultry diets have been recently evaluated (Surai and Fisinin, 2014 and references there) and the same points are relevant for pig nutrition. They can be summaries as follows:

- Se-Yeast contain Se-Met as a main Se compound, however, it represents no more than $60 \%$ to $70 \%$ of total Se. Recently, a considerable incorporation of selenocysteine (SeCys) in proteins of the yeast proteome despite the absence of the uracil-guanineadenine codon was demonstrated (Bierla et al., 2013). The authors concluded that $10 \%$ to $15 \%$ of selenium present in Se-enriched yeast is in the form of SeCys. This means, that if all Se in Se-Yeast is accounted for, 
the maximum SeMet proportion would not exceed $85 \%$, but in many cases will be lower than that.

- Se-Met proportions in Se-Yeast are quite variable and with the present technology, it is difficult to guarantee exact percentage of Se-Met in the product.

- There are analytical difficulties to precisely determine SeMet concentrations in the Yeast-based products and only a few labs worldwide can do such complex analysis.

Another option to improve Se status of poultry and farm animals would be to use pure SeMet as a dietary supplement (Schrauzer, 2000). There are some respectable publications showing beneficial effect of organic Se in the form of SeMet in the pig diets (Hu et al., 2011; Zhan et al., 2011). Recently it has been determined whether SeMet or Se-Yeast acts with different potency on six biochemical markers including intraprostatic dihydrotestosterone (DHT), testosterone (T), DHT:T, and epithelial cell DNA damage, proliferation, and apoptosis (Waters et al., 2012). By analyzing dogs supplemented with SeMet or Se-Yeast that achieved equivalent intraprostatic selenium concentration after supplementation, there was no significant differences in potency of either selenium form on any of the six parameters over three different ranges of target tissue selenium concentration. However, SeMet in purified form is unstable and easily oxidised. For example, it has been shown that in the freeze-dried samples of oyster total Se and the Se species evaluated are stable for at least 12 months, under all the conditions tested. However, after purification of Se species, including SeMet, in the enzymatic extracts they are only stable for $10 \mathrm{~d}$ if stored at $4^{\circ} \mathrm{C}$ in Pyrex containers (Moreno et al., 2002). After storage of SeMet water solution for $30 \mathrm{~d}$ at $20^{\circ} \mathrm{C}$, less than $80 \%$ SeMet was recovered (Lindemann et al., 2000). Potentially bioavailable selenium-containing compounds in the Se-Yeast were investigated using candidate reference material (Reyes et al., 2006). SeMet was the major compound identified in the gastrointestinal extract while SeMet selenoxide was its main degradation product formed after medium and longterm sample storage, respectively. The oxidability of SeMet during storage could explain different results in terms of gene expression between SeMet-supplemented and SeYeast-supplemented group of mice (Barger et al., 2012).

Recently a new stable organic Se source called Selisseo (SO) has been developed which is a seleno-hydroxymethionine, 2-hydroxy-4-methylselenobutanoic acid or HMSeBA Two experiments were conducted on broiler chickens (Briens et al., 2013; 2014) and one on laying hens (Jlali et al., 2013) to compare the effect of HMSeBA (SO), with two practical Se additives, SS and Se-Yeast. The results clearly shows that Selisseo fed in the same dosage as Se-Yeast significantly improved Se status of the growing chicks and laying hens with improved Se transfer to the egg.
The same was proven for pigs. Indeed, regardless the Se level, the Se deposition in muscle was significantly greater in pigs supplemented with SO than those supplemented with Se-Yeast. Slope ratio assay revealed that the relative bioavailability of Se from HMSeBA for plasma, liver, and muscle Se response was $170 \%, 141 \%$, and $162 \%$, respectively, in comparison to Se-Yeast (Jlali et al., 2014). Recently, EU limited the maximum supplementation with selenized yeast to $0.2 \mathrm{mg} \mathrm{Se} / \mathrm{kg}$ complete feed for reasons of consumer safety (Commission Implementing Regulation No. 427/2013 of 8 May 2013). It seems likely that at this comparatively low legal level of Se supplementation alternative effective sources of organic selenium with higher efficiency of transfer to the animal tissues would play an importsant role in pig reproduction.

Therefore, aforementioned results indicated that a new source of organic selenium in the form of 2-hydroxy-4methylselenobutanoic acid supplied in the same dose as SeYeast in the chicken and pig diets could provide additional benefit in terms of Se reserves in the muscles and one can expect higher Se levels in boar testes and semen as well as transfer to the progeny via placenta. This potentially can be translated into better antioxidant protection in stress conditions of commercial pig production and maintain boar reproductive performance and semen quality at high level.

\section{CONCLUSIONS}

From the information presented, it is clear that selenium plays an important role in boar nutrition. The requirement of swine for selenium varies depending on many environmental and other conditions and in general is considered 0.15 to $0.30 \mathrm{mg} / \mathrm{kg}$ feed. It seems likely that reproducing sows and boars are especially sensitive to Se deficiency, and to meeting their requirements is an important challenge for pig nutritionists. The analysis of data of various boar trials with different Se sources indicates, that in some cases when background Se levels were low, there were advantages of Se dietary supplementation. It is necessary to take into account that only an optimal Se status of animals is associated with the best antioxidant protection and could have positive effects on boar semen production and its quality. However, in many cases background Se levels were not determined and therefore it is difficult to judge if the basic diets were deficient in Se. It can also be suggested that, because of higher efficacy of assimilation from the diet, and possibilities of building Se reserves in the body, organic selenium in the form of SeMet provided by a range of products, including Se-Yeast and SeMet preparations is an important source of Se to better meet the needs of modern pig genotypes. 


\section{REFERENCES}

Ahsan, U., Z. Kamran, I. Raza, S. Ahmad, W. Babar, M. H. Riaz, and Z. Iqbal. 2014. Role of selenium in male reproduction A review. Anim. Reprod. Sci. 146:55-62.

Aitken, R. J., D. Harkiss, and D. Buckingham. 1993. Relationship between iron-catalysed lipid peroxidation potential and human sperm function. J. Reprod. Fertil. 98: 257-265.

Am-in, N., R. N. Kirkwood, M. Techakumphu, and W. Tantasuparuk. 2011. Lipid profiles of sperm and seminal plasma from boars having normal or low sperm motility. Theriogenology 75:897-903.

Audet, I., J. P. Laforest, G. P. Martineau, and J. J. Matte. 2004. Effect of vitamin supplements on some aspects of performance, vitamin status, and semen quality in boars. J. Anim. Sci. 82: 626-633.

Audet, I., N. Bérubé, J. L. Bailey, J. P. Laforest, H. Quesnel, and J. J. Matte. 2009. Effects of dietary vitamin supplementation and semen collection frequency on hormonal profile during ejaculation in the boar. Theriogenology 71:334-341.

Audet, I., N. Bérubé, J. L. Bailey, J. P. Laforest, and J. J. Matte. 2009a. Effects of dietary vitamin supplementation and semen collection frequency on reproductive performance and semen quality in boars. J. Anim. Sci. 87:1960-1970.

Awda, B. J. and M. M. Buhr. 2010. Extracellular signal-regulated kinases (ERKs) pathway and reactive oxygen species regulate tyrosine phosphorylation in capacitating boar spermatozoa. Biol. Reprod. 83: 750-758.

Awda, B. J., M. Mackenzie-Bell, and M. M. Buhr. 2009. Reactive oxygen species and boar sperm function. Biol. Reprod. 81: 553-561.

Bailey, J. L., J-F. Bilodeau, and N. Cormier. 2000. Semen cryopreservation in domestic animals: A damaging and capacitating phenomenon. J. Androl. 21: 1-7.

Barger, J. L., T. Kayo, T. D. Pugh, J. A. Vann, R. Power, K. Dawson, R. Weindruch, and T. A. Prolla. 2012. Gene expression profiling reveals differential effects of sodium selenite, selenomethionine, and yeast-derived selenium in the mouse. Genes Nutr. 7:155-165.

Bathgate, R. 2011. Antioxidant mechanisms and their benefit on post-thaw boar sperm quality. Reprod. Domest. Anim. 46(Suppl. 2):23-25.

Bierla, K., J. Bianga, L. Ouerdane, J. Szpunar, A. Yiannikouris, and R. A. Lobinski. 2013. A comparative study of the Se/S substitution in methionine and cysteine in Se-enriched yeast using an inductively coupled plasma mass spectrometry (ICP MS)-assisted proteomics approach. J. Proteomics 87:26-39.

Breininger, E., N. B. Beorlegui, C. M. O'Flaherty, and M. T. Beconi. 2005. Alpha-tocopherol improves biochemical and dynamic parameters in cryopreserved boar semen. Theriogenology 63:2126-2135.

Briens, M., Y. Mercier, F. Rouffineau, V. Vacchina, and P. A. Geraert. 2013. Comparative study of a new organic selenium source v. seleno-yeast and mineral selenium sources on muscle selenium enrichment and selenium digestibility in broiler chickens. Br. J. Nutr. 110:617-624.

Briens, M., Y. Mercier, F. Rouffineau, F. Mercerand, and P. A. Geraert. 2014. 2-hydroxy-4-methylselenobutanoic acid induces additional tissue selenium enrichment in broiler chickens compared with other selenium sources. Poult. Sci. 93:85-93.

Brigelius-Flohé, R. and M. Maiorino. 2013. Glutathione peroxidases. Biochim. Biophys. Acta. 1830:3289-3303.

Brouwers, J. F. and B. M. Gadella. 2003. In situ detection and localization of lipid peroxidation in individual bovine sperm cells. Free Radic. Biol. Med. 35:1382-1391.

Buhr, M. M., E. F. Curtis, and N. S. Kakuda. 1994. Composition and behavior of head membrane lipids of fresh and cryopreserved boar sperm. Cryobiology 31:224-238.

Calabrese, V., C. Cornelius, A.T. Dinkova-Kostova, I. Iavicoli, R. Di Paola, A. Koverech, S. Cuzzocrea, E. Rizzarelli, and E. J. Calabrese. 2012. Cellular stress responses, hormetic phytochemicals and vitagenes in aging and longevity. Biochim. Biophys. Acta. 1822:753-783.

Castellano, C. A., I. Audet, J. L. Bailey, J. P. Laforest, and J. J. Matte. 2010. Dietary omega-3 fatty acids (fish oils) have limited effects on boar semen stored at $17^{\circ} \mathrm{C}$ or cryopreserved. Theriogenology 74:1482-1490.

Chatterjee, S., E. de Lamirande, and C. Gagnon. 2001. Cryopreservation alters membrane sulfhydryl status of bull spermatozoa: protection by oxidized glutathione. Mol. Reprod. Dev. 60:498-506.

Cerolini, S., A. Maldjian, P. F. Surai, and R. C. Noble. 2000. Viability, susceptibility to peroxidation and fatty acid composition of boar semen during liquid storage. Anim. Reprod. Sci. 58:99-111.

Cerolini, S., A. Maldjian, F. Pizzi, and T. M. Gliozzi. 2001. Changes in sperm quality and lipid composition during cryopreservation of boar semen. Reproduction 121:395-401.

Chen, S. J., J. P. Allam, Y. G. Duan, and G. Haidl. 2013. Influence of reactive oxygen species on human sperm functions and fertilizing capacity including therapeutical approaches. Arch. Gynecol. Obstet. 288:191-199.

Comhaire, F. H., A. B. Christophe, A. A. Zalata, W. S. Dhooge, A. M. A. Mahmoud, and C. E. Depuydt. 2000. The effects of combined conventional treatment, oral antioxidants and essential fatty acids on sperm biology in subfertile men. Prostaglandins Leukot. Essent. Fatty Acids 63:159-165.

Conquer, J. A., J. B. Martin, I. Tummon, L. Watson, and F. Tekpetey. 1999. Fatty acid analysis of blood serum, seminal plasma, and spermatozoa of normozoospermic vs. asthernozoospermic males. Lipids 34:793-799.

Ferguson, L. R., N. Karunasinghe, S. Zhu, and A. H. Wang. 2012. Selenium and its' role in the maintenance of genomic stability. Mutat. Res. Fundam. Mol. Mech. Mutagen. 733: 100-110.

Fisinin, V. I., T. T. Papazyan, and P. F. Surai. 2008. Selenium in poultry nutrition. In: Current Advances in Se Research and Applications (Eds. P. F. Surai and J. Taylor-Pickard). Wageningen Academic Publishers, Wageningen, The Netherlands. pp. 221-261.

Flohe, L. and R. Zimmermann. 1970. The role of GSH peroxidase in protecting the membrane of rat liver mitochondria. Biochim. Biophys. Acta. 223: 210-213.

Fraser, L., J. Strzeżek, and W. Kordan. 2014. Post-thaw sperm characteristics following long-term storage of boar semen in liquid nitrogen. Anim. Reprod. Sci. 147:119-127.

Foresta, C., L. Flohe, A. Garolla, A. Roveri, F. Ursini, and M. 
Maiorino. 2002. Male fertility is linked to the selenoprotein phospholipid hydroperoxide glutathione peroxidase. Biol. Reprod. 67: 967-971.

Fortier, M. E., I. Audet, A. Giguère, J. P. Laforest, J. F. Bilodeau, H. Quesnel, and J. J. Matte. 2012. Effect of dietary organic and inorganic selenium on antioxidant status, embryo development, and reproductive performance in hyperovulatory first-parity gilts. J Anim Sci. 90:231-240.

Gadea, J., D. Gumbao, C. Matás, and R. Romar. 2005. Supplementation of the thawing media with reduced glutathione improves function and the in vitro fertilizing ability of boar spermatozoa after cryopreservation. J. Androl. 26: 749-756.

Gómez-Fernández, J., E. Gómez-Izquierdo, C. Tomás, E. Mocé, and E. de Mercado. 2013. Is sperm freezability related to the post-thaw lipid peroxidation and the formation of reactive oxygen species in boars? Reprod. Domest. Anim. 48:177-182.

Griveau, J. F., E. Dumont, P. Renard, J. P. Callegari, and D. LeLannou. 1995. Reactive oxygen species, lipid peroxidation and enzymatic defence systems in human spermatozoa. J. Reprod. Fertil. 103: 17-26.

Guerriero, G., S. Trocchia, F. K. Abdel-Gawad, and G. Ciarcia 2014. Roles of reactive oxygen species in the spermatogenesis regulation. Front. Endocrinol. (Lausanne). 5:56. eCollection 2014.

Halliwell, B. 1994. Free radicals and antioxidants: A personal view. Nutr. Rev. 52:253-265.

Halliwell, B. and J. M. C. Gutteridge. 1999. Free Radicals in Biology and Medicine. Third Edition. Oxford University Press, Oxford, UK.

Hatfield, D. L., P. A. Tsuji, B. A. Carlson, and V. N. Gladyshev. 2014. Selenium and selenocysteine: Roles in cancer, health, and development. Trends Biochem. Sci. 39:112-120.

Horky, P., P. Jancikova, J. Sochor, D. Hynek, G. J. Chavis, B. Ruttkay-Nedecky. N. Cernei, O. Zitka, L. Zeman, V. Adam, and R. Kizek. 2012. Effect of organic and inorganic form of selenium on antioxidant status of breeding boars ejaculate revealed by electrochemistry. Int. J. Electrochem. Sci. 7: 96439657.

Hu, H., M. Wang, X. Zhan, X. Li, and R. Zhao. 2011. Effect of different selenium sources on productive performance, serum and milk Se concentrations, and antioxidant status of sows. Biol. Trace Elem. Res. 142:471-480.

Hu, J., G. Geng, Q. Li, X. Sun, H. Cao, and Y. Liu. 2014. Effects of alginate on frozen-thawed boar spermatozoa quality, lipid peroxidation and antioxidant enzymes activities. Anim. Reprod. Sci. 147:112-118

Imai, H. and Y. Nakagawa. 2003. Biological significance of phospholipid hydroperoxide glutathione peroxidase (PHGPx, GPx4) in mammalian cells. Free Radic. Biol. Med. 34:145-169.

Imai, H., K. Suzuki, K. Ishizaka, S. Ichinose, H. Oshima, I. Okayasu, K. Emoto, M. Umeda, and Y. Nakagawa. 2001. Failure of the expression of phospholipid hydroperoxide glutathione peroxidase in the spermatozoa of human infertile males. Biol. Reprod. 64:674-683.

Jelezarsky, L., Ch. Vaisberg, T. Chaushev, and E. Sapundjiev. 2008. Localization and characterization of glutathione peroxidase (GPx) in boar accessory sex glands, seminal plasma, and spermatozoa and activity of GPx in boar semen. Theriogenology 69:139-145.

Jlali, M., M. Briens, F. Rouffineau, F. Mercerand, P. A. Geraert, and Y. Mercier. 2013. Effect of 2-hydroxy-4methylselenobutanoic acid as a dietary selenium supplement to improve the selenium concentration of table eggs. J. Anim. Sci. 91:1745-1752.

Jlali, M., M. Briens, F. Rouffineau, P. A. Geraert, and Y. Mercier. 2014. Evaluation of the efficacy of 2-hydroxy-4methylselenobutanoic acid on growth performance and tissue selenium retention in growing pigs. J. Anim. Sci. 92:182-188.

Kolodziej, A. Q. and E. Jacyno. 2005. Effect of selenium and vitamin $\mathrm{E}$ supplementation on reproductive performance of young boars. Arch. Tierz., Dummerstorf. 48: 68-75.

Kowalowka, M., P. Wysocki, L. Fraser, and J. Strzezek. 2008. Extracellular superoxide dismutase of boar seminal plasma. Reprod. Domest. Anim. 43:490-496.

Koziorowska-Gilun, M., M. Koziorowski, L. Fraser, and J. Strzeżek. 2011. Antioxidant defence system of boar cauda epididymidal spermatozoa and reproductive tract fluids. Reprod. Domest. Anim. 46:527-533.

Kumaresan, A., G. Kadirvel, K. M. Bujarbaruah, R. K. Bardoloi, A. Das, S. Kumar, and S. Naskar. 2009. Preservation of boar semen at 18 degrees $\mathrm{C}$ induces lipid peroxidation and apoptosis like changes in spermatozoa. Anim. Reprod. Sci. 110:162-171.

Labunskyy, V. M., D. L. Hatfield, and V. N. Gladyshev. 2014. Selenoproteins: Molecular pathways and physiological roles. Physiol. Rev. 94:739-777.

Ladha, S. 1998. Lipid heterogeneity and membrane fluidity in a highly polarized cell, the mammalian spermatozoon. J. Membr. Biol. 165:1-10.

Lei, X. G., J. K. Evenson, K. M. Thompson, and R. A. Sunde. 1995. Glutathione peroxidase and phospholipid hydroperoxide glutathione peroxidase are differentially regulated in rats by dietary selenium. J. Nutr. 125:1438-1446.

Lenzi, A., L. Gandini, V. Maresca, R. Rago, P. Sgro, F. Dondero, and M. Pivardo. 2000. Fatty acid composition of spermatozoa and immature germ cells. Mol. Hum. Reprod. 6: 226-231.

Li, T. K. 1975. The glutathione and thiol content of mammalian spermatozoa and seminal plasma. Biol. Reprod. 12: 641-646.

Lindemann, T., A. Prange, W. Dannecker, and B. Neidhart. 2000. Stability studies of arsenic, selenium, antimony and tellurium species in water, urine, fish and soil extracts using HPLC/ICPMS. Fresenius J. Anal. Chem. 368:214-220.

López, A., T. Rijsselaere, A. Van Soom, J. L. M. R. Leroy, J. B. P. De Clercq, P. E. J. Bols, and D. Maes. 2010. Effect of organic selenium in the diet on sperm quality of boars. Reprod. Domest. Anim. 45:e297-e305.

Lovercamp, K. W., K. R. Stewart, X. Lin, and W. L. Flowers. 2013. Effect of dietary selenium on boar sperm quality. Anim. Reprod. Sci. 138:268-275.

Luberda, Z. 2005. The role of glutathione in mammalian gametes. Reprod. Biol. 5:5-17.

Mahan, D., J. Zawadzki, and R. Guerrero. 2002. Mineral metabolism and boar fertility: Observations from Latin America to Europe. In: Nutritional Biotechnology in the Feed and Food Industries (Eds. T. P. Lyons and K. A. Jacques). 
Nottingham University Press, Nottingham, UK. pp. 411-418.

Mahan, D. C., T. R. Cline, and B. Richert. 1999. Effects of dietary levels of selenium-enriched yeast and sodium selenite as selenium sources fed to growing-finishing pigs on performance, tissue selenium, serum glutathione peroxidase activity, carcass characteristics, and loin quality. J. Anim. Sci. 77: 2172-2179

Mangiapane, E., A. Pessione, and E. Pessione. 2014. Selenium and selenoproteins: An overview on different biological systems. Curr. Protein Pept. Sci. 15:598-607.

Marin-Guzman, J., D. C. Mahan, Y. K. Chung, J. L. Pate, and W. F. Pope. 1997. Effects of dietary selenium and vitamin $\mathrm{E}$ on boar performance and tissue responses, semen quality, and subsequent fertilization rates in mature gilts. J. Anim. Sci. 75: 2994-3003.

Marin-Guzman, J., D. C. Mahan, and R. Whitmoyer. 2000. Effect of dietary selenium and vitamin $\mathrm{E}$ on the ultrastructure and ATP concentration of boar spermatozoa, and the efficacy of added sodium selenite in extended semen on sperm motility. J. Anim. Sci. 78:1544-1550.

Marin-Guzman, J., D. C. Mahan, and J. L. Pate. 2000a. Effect of dietary selenium and vitamin $\mathrm{E}$ on spermatogenic development in boars. J. Anim. Sci. 78: 1537-1543.

Martins, S. M., A. F. De Andrade, F. G. Zaffalon, F. F. Bressan, S. M. Pugine, M. P. Melo, M. R. Chiaratti, C. T. Marino, A. S. Moretti, and R. P. Arruda. 2015. Organic selenium supplementation increases PHGPx but does not improve viability in chilled boar semen. Andrologia 17:85-90.

Moreno, P., M. A. Quijano, A. M. Gutierrez, M. C. Perez-Conde, and C. Camara. 2002. Stability of total selenium and selenium species in lyophilised oysters and in their enzymatic extracts. Anal. Bioanal. Chem. 374: 466-476.

Naher, Z. U., M. Ali, S. K. Biswas, F. H. Mollah, P. Fatima, M. M. Hossain, and M. I. Arslan. 2013. Effect of oxidative stress in male infertility. Mymensingh Med. J. 22:136-142.

Nenicu, A., G. H. Luers, W. Kovacs, M. Bergmann, and E. Baumgart-Vogt. 2007. Peroxisomes in human and mouse testis: differential expression of peroxisomal proteins in germ cells and distinct somatic cell types of the testis. Biol. Reprod. 77: 1060-1072.

National Research Council. 1998. Nutrient Requirement of Swine, 10th Revised Edition, National Academies Press, Washington, DC, USA.

Orzołek, A., P. Wysocki, J. Strzeżek, and W. Kordan. 2013. Superoxide dismutase (SOD) in boar spermatozoa: Purification, biochemical properties and changes in activity during semen storage $\left(16^{\circ} \mathrm{C}\right)$ in different extenders. Reprod. Biol. 13:34-40.

Parrilla, I., D. del Olmo, L. Sijses, M. J. Martinez-Alborcia, C. Cuello, J. M. Vazquez, E. A. Martinez and J. Roca. 2012. Differences in the ability of spermatozoa from individual boar ejaculates to withstand different semen-processing techniques. Anim. Reprod. Sci. 132:66-73.

Payne, R. L. and L. L. Southern. 2005. Changes in glutathione peroxidase and tissue selenium concentrations of broilers after consuming a diet adequate in selenium. Poult. Sci. 84:12681276.

Poulos, A., A. Darin-Bennett, and I. G. White. 1973. The phospholipid-bound fatty acids and aldehydes of mammalian spermatozoa. Comp. Biochem. Physiol. Part B. Comp.
Biochem. 46B:541-549.

Radomil, L., M. J. Pettitt, K. M. Merkies, K. D. Hickey, and M. M. Buhr. 2011. Stress and dietary factors modify boar sperm for processing. Reprod. Domest. Anim. 46(Supp 12 ):39-44.

Reyes, H. L., J. M. Marchante-Gayón, J. I. García Alonso, and A. Sanz-Medel. 2006. Application of isotope dilution analysis for the evaluation of extraction conditions in the determination of total selenium and selenomethionine in yeast-based nutritional supplements. J. Agric. Food Chem. 54:1557-1563.

Saaranen, M., U. Suistomaa, and T. Vanha-Perttula. 1989. Semen selenium content and sperm mitochondrial volume in human and some animal species. Hum. Reprod. 4: 304-308.

Satorre, M. M., E. Breininger, and M. T. Beconi. 2012. Cryopreservation with $\alpha$-tocopherol and Sephadex filtration improved the quality of boar sperm. Theriogenology 78:15481556.

Schneider, M., H. Förster, A. Boersma, A. Seiler, H. Wehnes, F. Sinowatz, C. Neumüller, M. J. Deutsch, A. Walch, M. Hrabé de Angelis, W. Wurst, F. Ursini, A. Roveri, M. Maleszewski, M. Maiorino, and M. Conrad. 2009. Mitochondrial glutathione peroxidase 4 disruption causes male infertility. FASEB J. 23: 3233-3242.

Schrauzer, G. N. 2000. Selenomethionine: A review of its nutritional significance, metabolism and toxicity. J. Nutr. 130: 1653-1656.

Segerson, E. C., W. R. Getz, and B. H. Johnson. 1981. Selenium and reproductive function in boars fed a low selenium diet. J. Anim. Sci. 53:1360-1367.

Speight, S. M., M. J. Estienne, A. F. Harper, R. J. Crawford, J. W. Knight, and B. D. Whitaker. 2012. Effects of dietary supplementation with an organic source of selenium on characteristics of semen quality and in vitro fertility in boars. J. Anim. Sci. 90:761-770.

Speight, S. M., M. J. Estienne, A. F. Harper, C. R. Barb, and T. D. Pringle. 2012a. Effects of organic selenium supplementation on growth performance, carcass measurements, tissue selenium concentrations, characteristics of reproductive organs, and testis gene expression profiles in boars. J. Anim. Sci. 90: 533-542.

Strzeżek, J. 2002. Secretory activity of boar seminal vesicle glands. Reprod. Biol. 2:243-266.

Strzezek, J., S. Lapkiewicz, and M. Lecewicz. 1999. A note of antioxidant capacity of boar seminal plasma. Anim. Sci. Pap. Rep. 17:181-188.

Strzeżek, J., P. Wysocki, W. Kordan, M. Kuklińska, M. Mogielnicka, D. Soliwoda, and L. Fraser. 2005. Proteomics of boar seminal plasma - current studies and possibility of their application in biotechnology of animal reproduction. Reprod. Biol. 5:279-290.

Sunde, R. A. 1994. Intracellular glutathione peroxidases structure, regulation, and function. In: Selenium in Biology and Human Health (Ed. R.F. Burk). Springer-Verlag, NewYork, USA. pp. 45-77.

Surai, P. F. 2002. Natural Antioxidants in Avian Nutrition and Reproduction. Nottingham University Press, Nottingham, UK.

Surai, P. F. 2006. Selenium in Nutrition and Health. Nottingham University Press, Nottingham, UK.

Surai, P. F. and V. I. Fisinin. 2014. Selenium in poultry breeder nutrition: An update. Anim. Feed Sci. Technol. 191:1-15. 
Surai, P. F., N. Fujihara, B. K. Speake, J-P. Brillard, G. J. Wishart, and N. H. C. Sparks. 2001. Polyunsaturated fatty acids, lipid peroxidation and antioxidant protection in avian semen. Review -. Asian Australas. J. Anim. Sci. 14:1024-1050.

Surai, P. F., A. C. Pappas, F. Karadas, T. T. Papazyan, and V. I. Fisinin. 2010. Selenium enigma: Health implications of an inadequate supply. In: Modern Dietary Fat Intakes in Disease Promotion (Eds. Fabien De Meester, Sheerna Zibadi, and Donald Ross Watson). Humana Press, New York, USA. pp. 379-403.

Tareq, K. M. A., Q. S. Akter, M. A. M. Khandoker, and H. Tsujii. 2012. Selenium and vitamin $\mathrm{E}$ improve the in vitro maturation, fertilization and culture to blastocyst of porcine oocytes. J. Reprod. Dev. 58:621-628.

Thongchalam, K., T. Rukkwamsuk, and S. Chopmchai. 2012. Blood and semen selenium concentrations and semen quality in boars fed diets supplemented with organic or inorganic selenium. J. Anim. Vet. Adv. 11:603-608.

Ursini, F., S. Heim, M. Kiess, M. Maiorino, A. Roveri, J. Wissing, and L. Flohe. 1999. Dual function of the selenoprotein PHGPx during sperm maturation. Science 285:1393-1396.

Ursini, F., M. Maiorino, and C. Gregolin. 1985. The selenoenzyme phospholipid hydroperoxide glutathione peroxidase. Biochim. Biophys. Acta 839:62-70.

Vernet, P., E. Rock, A. Mazur, Y. Rayssiguier, J. P. Dufaure, and J. R. Drevet. 1999. Selenium-independent epididymis-restricted glutathione peroxidase 5 protein (GPX5) can back up failing Se-dependent GPXs in mice subjected to selenium deficiency. Mol. Reprod. Dev. 54:362-370.
Vernet, P., R. J. Aitken, and J. R. Drevet. 2004. Antioxidant strategies in the epididymis. Mol. Cell. Endocrinol. 216: 31-39.

Walczak-Jedrzejowska, R., J. K. Wolski, and J. SlowikowskaHilczer. 2013. The role of oxidative stress and antioxidants in male fertility. Cent. European J. Urol. 66:60-67.

Waters, D. J., S. Shen, S. S. Kengeri, E. C. Chiang, G. F. Jr. Combs, J. S. Morris, and D. G. Bostwick. 2012. Prostatic response to supranutritional selenium supplementation: Comparison of the target tissue potency of selenomethionine vs. selenium-yeast on markers of prostatic homeostasis. Nutrients 4:1650-1663.

Wright, C., S. Milne, and H. Leeson. 2014. Sperm DNA damage caused by oxidative stress: Modifiable clinical, lifestyle and nutritional factors in male infertility. Reprod. Biomed. Online 28:684-703.

Zelko, I. N., T. J. Mariani, and R. J. Folz. 2002. Superoxide dismutase multigene family: A comparison of the CuZn-SOD (SOD1), Mn-SOD (SOD2), and EC-SOD (SOD3) gene structures, evolution, and expression. Free Rad. Biol. Med. 33: 337-349.

Zhan, X., Y. Qie, M. Wang, X. Li, and R. Zhao. 2011. Selenomethionine: An effective selenium source for sow to improve Se distribution, antioxidant status, and growth performance of pig offspring. Biol. Trace Elem. Res. 142:481491.

Zhang, Q., L. Chen, K. Guo, L. Zheng, B. Liu, W. Yu, C. Guo, Z. Liu, Y. Chen, and Z. Tang. 2013. Effects of different selenium levels on gene expression of a subset of selenoproteins and antioxidative capacity in mice. Biol. Trace Elem. Res. 154: 255-261. 